Document downloaded from:

http://hdl.handle.net/10251/150681

This paper must be cited as:

Margarit Benavent, VJ.; Osman, M.; Al-Khattaf, S.; Martínez, C.; Boronat Zaragoza, M.; Corma Canós, A. (2019). Control of the Reaction Mechanism of Alkylaromatics Transalkylation by Means of Molecular Confinement Effects Associated to Zeolite Channel Architecture. ACS Catalysis. 9(7):5935-5946. https://doi.org/10.1021/acscatal.9b00763

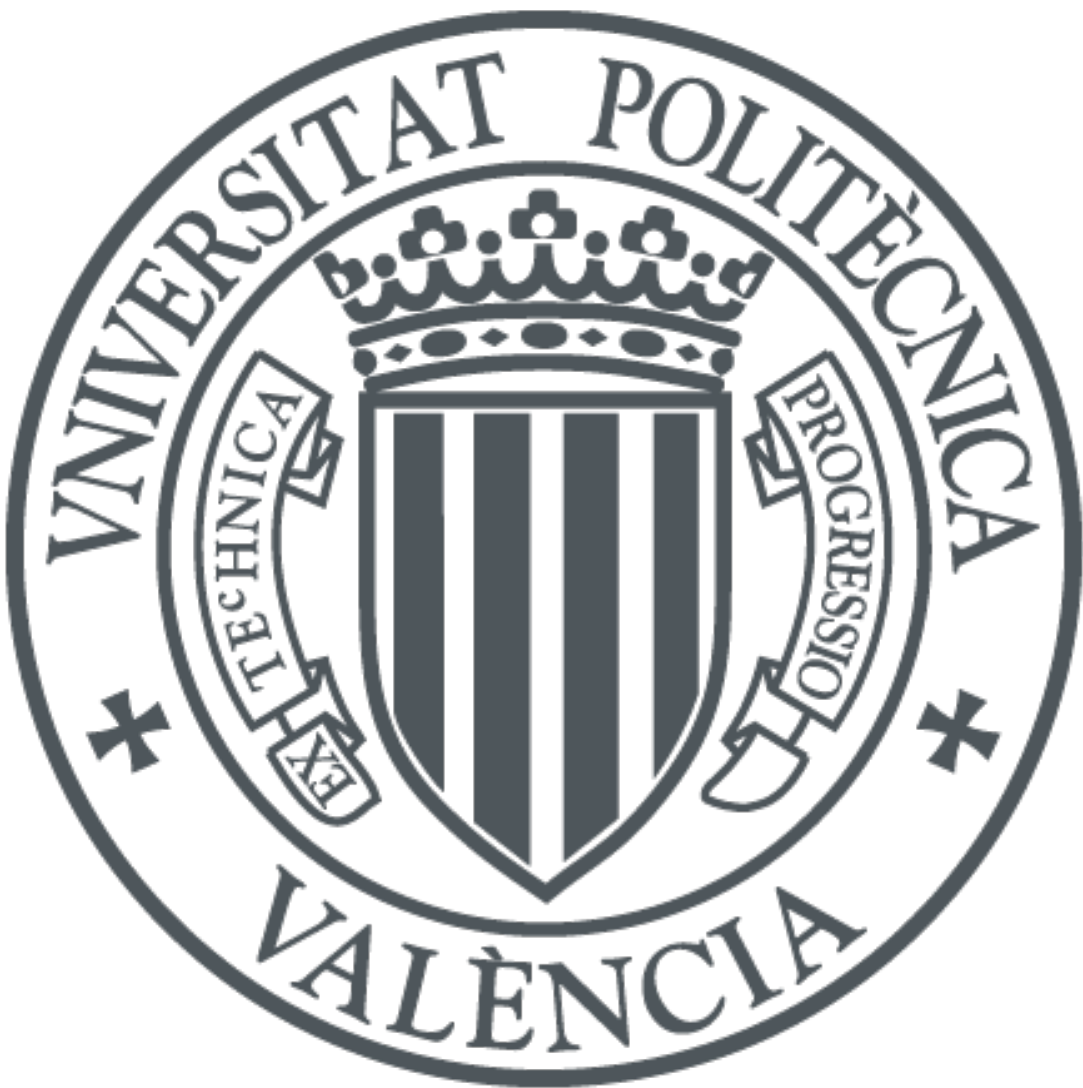

The final publication is available at

https://doi.org/10.1021/acscatal.9b00763

Copyright American Chemical Society

Additional Information

"This document is the Accepted Manuscript version of a Published Work that appeared in final form in ACS Catalysis, copyright (C) American Chemical Society after peer review and technical editing by the publisher. To access the final edited and published work see https://doi.org/10.1021/acscatal.9b00763" 


\title{
Control of the Reaction Mechanism of Alkylaromatics Transalkylation by Means of Molecular Confinement Effects Associated to Zeolite Channel Architecture
}

\author{
Vicente J. Margarit, ${ }^{1}$ Mogahid Osman, ${ }^{2}$ Sulaiman Al-Khattaf, ${ }^{2}$ Cristina Martínez, ${ }^{1}$ Mercedes \\ Boronat, ${ }^{1 *}$ and Avelino Corma ${ }^{1 *}$ \\ ${ }^{1}$ Instituto de Tecnología Química, Universitat Politècnica de València - Consejo Superior de Investigaciones \\ Cientificas, Av. de los Naranjos, s/n, 46022 Valencia, Spain \\ ${ }^{2}$ Center of Research Excellence in Petroleum Refining \& Petrochemicals, King Fahd University of Petroleum \\ \& Minerals, 31261 Dhahran, Saudi Arabia
}

Supporting Information

\begin{abstract}
Transalkylation of alkylaromatics catalyzed by acid zeolites is a process widely employed in the petrochemical industry for upgrading aromatic fractions. The reaction mechanism is complex as it can proceed either by intermolecular alkyl-transfer involving dealkylation-alkylation steps with surface alkoxy species as reaction intermediates, or through the formation of bulkier diaryl intermediates. We have investigated how the possible formation of such bulky intermediates in the microporous channel system of different zeolite structures, together with their stabilization by confinement effects, can determine the preferential mechanism and, therefore, the selectivity of ethylbenzene disproportionation into benzene and diethylbenzene. For testing the concept, four zeolites, MCM-22 (3D MWW) with 10R pores, 12R cavities and external 12R hemicavities or "cups", DS-ITQ-2, a 2D MWW with the same 10R channels as MCM-22, no $12 \mathrm{R}$ cavities and much larger proportion of external "cups", a 10R ZSM-5 (MFI) and a 12R mordenite (MOR) have been used. The higher activity of DSITQ-2 and MCM-22 as compared to ZSM-5, at low temperature $(573 \mathrm{k})$ and the high selectivity to diethylbenzene of the bidimensional material under all reaction conditions considered have been explained by means of DFT calculations. Contrary to what could be expected according to the available space at the external "cups" and at the 10R channels of the MWW structure, the bulkier diaryl intermediates are better stabilized within the 10R channel system than at the "cups" open at the external surface of the MWW materials. We show from this perspective how the channel structure and molecular confinement stabilization also explain the operating reaction mechanism in ZSM-5 and mordenite.
\end{abstract}

KEYWORDS: Zeolites, MWW structure, molecular confinement, ethylbenzene transalkylation, DFT, transalkylation mechanism.

\begin{abstract}
1. INTRODUCTION
Zeolites are microporous materials largely used as industrial heterogeneous catalysts. This is due to the large variety of welldefined microporous structures available, the flexibility regarding their chemical composition, their thermal and hydrothermal stability and their environmentally benign properties. ${ }^{1,2}$ Their main applications within the petrochemical field are related to upgrading aromatic fractions. In general terms, alkylaromatics can be converted by means of Brönsted acid catalyzed disproportionation/ transalkylation, isomerization and dealkylation-alkylation reactions and, although the reactivity of the alkylaromatic and the reaction conditions play a role on product selectivity, the extension of each of these competing processes mainly depends on the structural and physico-chemical properties of the zeolite catalyst. ${ }^{3-}$

${ }^{6}$ Thus, the zeolite topology, the size and dimensionality of the channel systems, the presence or absence of intersections and/or cavities, combined with the confinement effects can determine the selectivity to the desired products by controlling the extension of competing parallel or consecutive reactions. ${ }^{7-11}$
\end{abstract}

The complexity of the alkylaromatics conversion processes has led to numerous studies regarding the possible reaction mechanisms within the microporous structure of medium, ${ }^{12-25}$ large ${ }^{14,15,19,26-32}$ and multipore ${ }^{33,34}$ zeolites. Focusing on the transalkylation of alkylbenzenes, it can either proceed by intermolecular alkyltransfer involving dealkylation-alkylation steps with surface alkoxy species as reaction intermediates, or through formation of bulkier diaryl intermediates ${ }^{19}$ (see Scheme 1). The contribution of these two mechanisms to the overall process depends on the relative stability of alkylaromatic and bulkier diaryl cationic intermediates, and is largely influenced by the size of the reactant, the zeolite pores and by the presence of channel intersections or cavities. In this sense, there is general agreement that the diaryl- 
mediated pathway (or variants like the dual-cycle proposed by Huong et al. ${ }^{17}$ ) is the dominant mechanism in large-pore zeolites like FAU and MOR, where no spatial restrictions for formation of bulky intermediates are expected, ${ }^{15,35}$ but there is still controversy about the processes taking place in medium-pore zeolites. Thus, diphenylmethane intermediates have been observed for toluene disproportionation in ZSM-5, a 10-ring zeolite without cavities, ${ }^{12}$ but only the ethoxy groups involved in the alkyl-transfer pathway were detected in the disproportionation of ethylbenzene on the same catalyst, ${ }^{19}$ suggesting a critical role of the fitting of the molecule within the pore architecture on the preferred mechanism. The presence of cavities in medium pore zeolites might favor the formation of bulkier intermediates and products as di-ethylated diphenylethane derivatives ${ }^{17}$ and the extension of consecutive reactions, ${ }^{33}$ but these bulkier by-products do not always diffuse out of the cavities and lead to fast deactivation of the catalyst, as observed for xylene ${ }^{23}$ and ethylbenzene ${ }^{17}$ disproportionation in the 12-ring cavities of MCM-22. On the other hand, only low amounts of diaryl intermediates were detected within the intra-layer medium-pore channel system of its delaminated counterpart ITQ-2 during ethylbenzene disproportionation, ${ }^{17}$ suggesting a small contribution of these 10-ring pores to the overall conversion of the alkylaromatic.

\section{alkyl-transfer pathway}

diaryl-mediated pathway
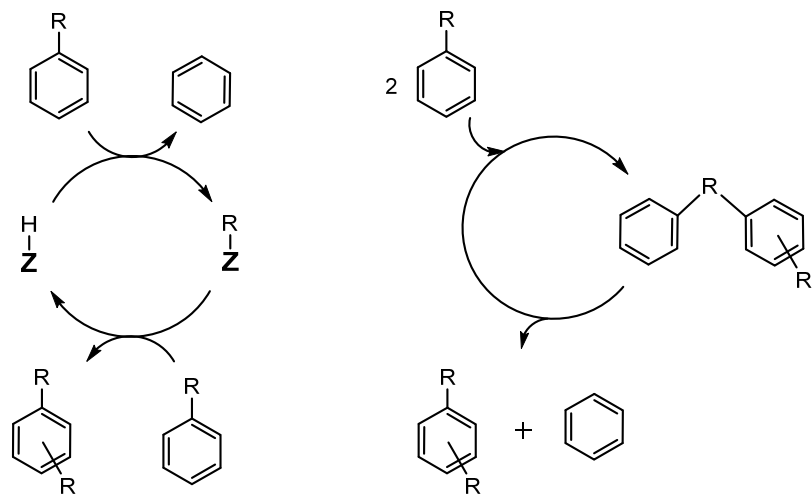

Scheme 1. Simplified mechanisms for disproportionation of alkylbenzenes.

In general, these attempts to explain structure-activity and structure-selectivity relationships in the transalkylation of alkylaromatics are based on the analysis of spatial restrictions for the formation and/or diffusion of diaryl intermediates, assuming that larger spaces in the zeolite structure favor the pathways involving bulkier intermediates or transition states. However, this simplified picture can be modified when confinement effects are taken into consideration. The confinement effect ${ }^{8,36-42}$ associates the enhanced catalytic properties of zeolites to an optimized stabilization of the cationic intermediates located in the microporous voids, not only by electrostatics, but also by van der Waals interactions with the surrounding framework oxygen atoms. The extent of this stabilization depends on the number of contacts between the guest molecule and the host zeolite, and is very sensitive to the size and shape of the adsorbed species and to their fitting with the framework environment. Based on this concept, reaction-adapted zeolites with only small differences in the shape of their cages, have been recently synthesized for different reactions by using mimics of the transition state as organic structure directing agent (OSDA). ${ }^{8,43}$ The resulting zeolites have been successfully applied to favor the preferred mechanism and, therefore, to control, for instance, the selectivity to ethene and propene in the methanol to olefins (MTO) reaction. ${ }^{43}$

In the case of alkylaromatics transalkylation, consideration of confinement effects suggests that the stability of the bulky diaryl intermediates could be finely tuned not only by avoiding spatial restrictions through the use of large pore zeolites, but specially by finding zeolite structures whose microporous voids could maximize the number of host-guest contacts. In this work, we show how the dimensions and especially the geometry of the channels and the molecular confinement effects associated can determine the reaction mechanism for ethylbenzene disproportionation. This has been possible by using complementary zeolites such as MCM-22, ITQ-2, ZSM-5 and mordenite. The selection has been based on the fact that MCM-22 contains two independent channel systems, one formed by 10-ring pores and a second one formed by 12-ring supercages accessible through 10-ring windows, and an external surface presenting large hemi-cavities or "cups", whereas the bidimensional ITQ-2 catalyst presents the same 10-ring channels as MCM-22, but no 12-ring cavities and a larger proportion of external "cups". The particular bi-dimensional DS-ITQ-2 zeolite employed is achieved by direct synthesis (DS) through a one-step procedure, ${ }^{44}$ and its interest relies on the fact that the microporous structure of the layers and, therefore, also the medium-pore 10-ring channel system running within these layers, are very well preserved. Finally, zeolites ZSM-5 and mordenite, a medium pore with 10-ring channels and a large pore with 12-ring channels zeolite, respectively, complete the comparison set. The catalytic disproportionation of ethylbenzene has been carried out in a fluidized-bed batch reactor, and the kinetic results have been combined with DFT theoretical calculations on the reactions occurring in the different zeolite structures. We show that the molecular confinement and the stabilization of reaction intermediates by dispersion forces can be critical for the mechanism selection and, consequently, for product distribution.

\section{RESULTS AND DISCUSSION}

2.1. DFT study. We present first a periodic DFT theoretical study of the relative stability of the most relevant intermediate species involved in the ethyl-transfer and diaryl-mediated mechanisms (Scheme 1) proposed for ethylbenzene disproportionation in different locations within the microporous structure of MOR, MFI and MWW. The objective is to determine the role of the confinement effect associated to the geometrical fitting of the carbocationic intermediates within the zeolite channels and cavities on the possible preferential stabilization of one of the two mechanisms proposed, with the corresponding changes in selectivity.

The structure of MOR contains parallel large 12-ring $(6.5 \times 7.0 \AA)$ and narrow 8-ring $(2.6 \times 5.7 \AA)$ channels along the $\mathrm{c}$ axis, interconnected by 8 -ring pockets $(3.4 \times 4.8 \AA)$ along the $\mathrm{b}$ axis (see Figure 1A), and only the large 12-ring channels were considered in the theoretical study. The 3D channel system of MFI crystal structure is composed by interconnected straight and sinusoidal 10ring channels $(5.3 \times 5.6 \AA$ and $5.1 \times 5.5 \AA$, respectively) that intersect perpendicularly forming larger void spaces of $\sim 7.0 \AA$ diameter (see Figure 1B-D). Both the straight and sinusoidal 10ring channels, as well as their intersection, were considered as 
possible locations to host cationic intermediates in MFI, and these sites are labeled as MFI-str, MFI-sin and MFI-int in Tables 1-2. MWW crystal structure presents two independent pore systems: a 2D sinusoidal 10-ring channel system $(4.1 \times 5.1 \AA)$ running within the layers, and a second one formed by 12-ring supercages $(7.1 \times$ $7.1 \times 18.2 \AA$ ) accessible through 10-ring windows. Moreover, large hemi-cavities or "cups" $(7.1 \times 7.1 \times 7.1 \AA)$ are present in the external surface of MCM-22 and in the layers of the delaminated DS-ITQ-2 zeolites (see Figure 1E-F). The stability of the reaction intermediates in the MWW framework was calculated both within the sinusoidal 10-ring channels and in the 12-ring external "cups".
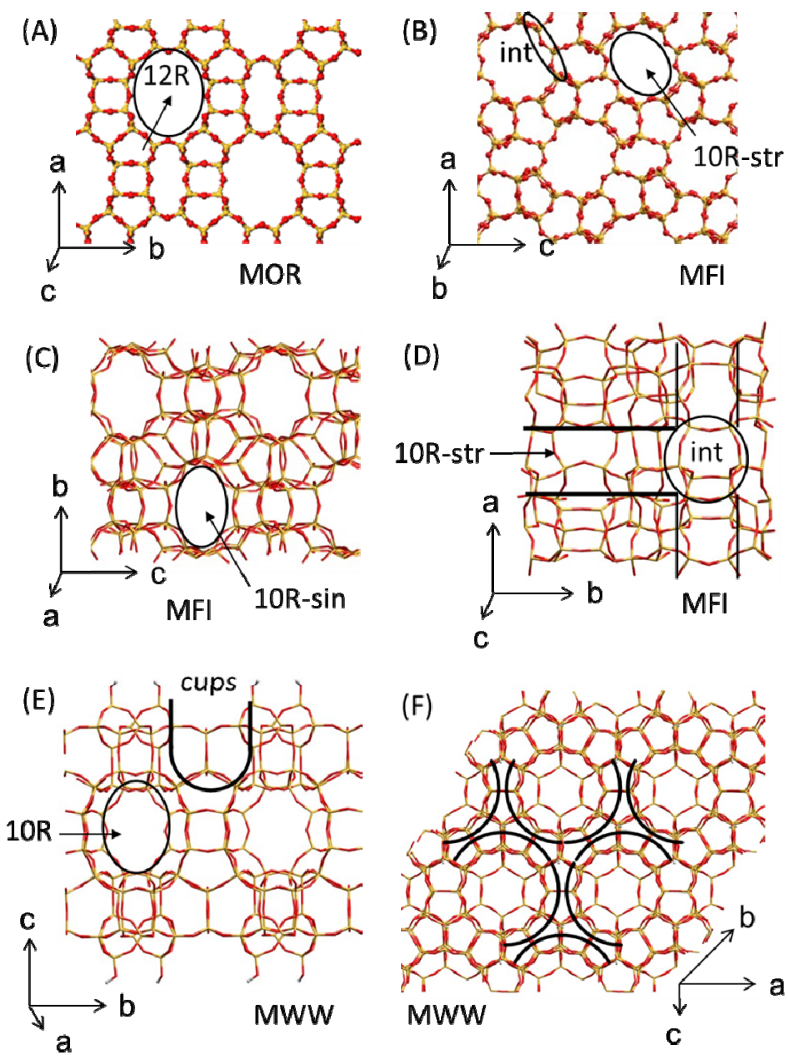

Figure 1. View of the 12-ring channels of MOR (A), of the straight (B) and sinusoidal (C) 10-ring pores of MFI, of their intersection (D), and of the 10-ring channels (E) and 12-ring cups (F) of MWW.

As mentioned in the Introduction, ethylbenzene disproportionation may proceed through two mechanisms, the alkyl-transfer and the diaryl-mediated pathways, shown in detail in Scheme 2. ${ }^{19}$ The alkyl-transfer pathway (Scheme 2A) starts with protonation of the reactant $\mathrm{R}$ forming a carbonium ion $\mathrm{RH}^{+}$that decomposes into benzene and an ethoxy group stabilized by covalent bonding to the zeolite framework $(\mathrm{Z}-\mathrm{Et}+\mathrm{Bz})$. Subsequent reaction with a second ethylbenzene molecule yields a dialkylcarbonium ion $\mathrm{PH}^{+}$that produces the diethylbenzene product $\mathrm{P}$ by proton transfer to the zeolite, thus closing the catalytic cycle. In this route, the ethoxy intermediate can also decompose into ethene and a Brönsted site, in an undesired dealkylation process.

The protonation of toluene and xylene to form carbonium ions $\mathrm{RH}^{+}$ has been previously investigated in TON, FAU, MFI and MOR zeolite structures using different theoretical approaches, and activation and reaction energies of 27 and 21-26 kcal $/ \mathrm{mol}$, respectively, have been reported. ${ }^{15,28}$ Therefore, we have initially associated the viability of the alkyl-transfer pathway with the possibility of formation of the carbonium ion $\mathrm{RH}^{+}$by protonation of adsorbed ethylbenzene. The data used to analyze the influence of the zeolite pore size and shape on the stabilization of protonated ethylbenzene are presented in Tables 1, S1, Figures 2, S1 and S2.
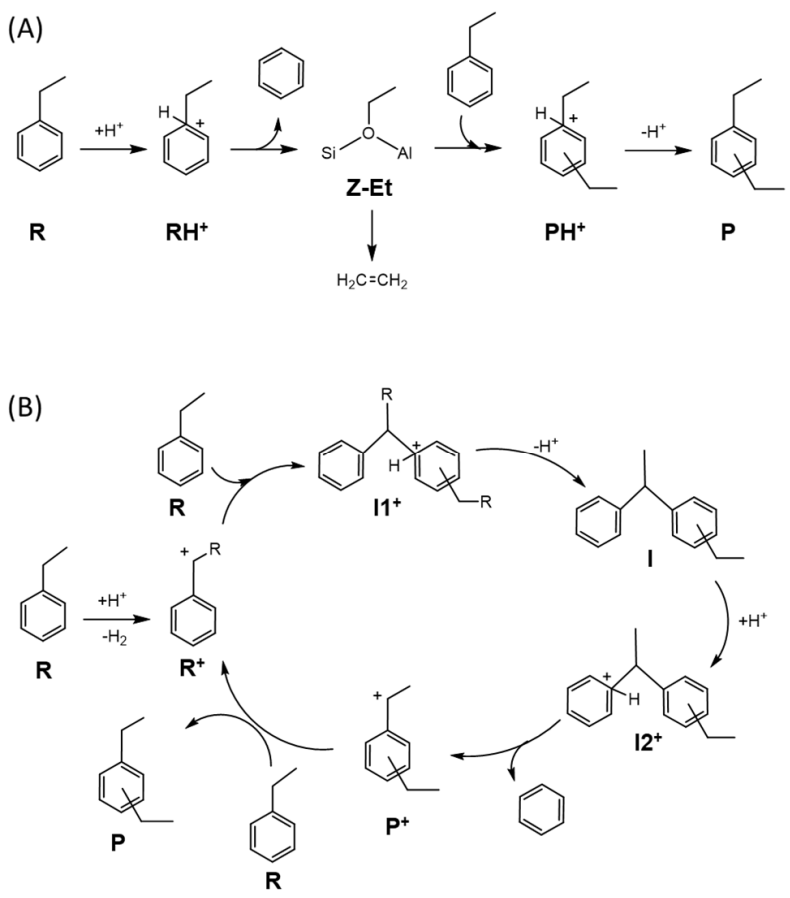

Scheme 2. Possible mechanisms for ethylbenzene disproportionation: (A) alkyl-transfer, and (B) diaryl-mediated pathways.

Ethylbenzene interaction with the Brönsted acid sites is weak, but the reactant molecule is highly stabilized within the zeolite pores by dispersion interactions. The dispersion-corrected Gibbs free energies $\left(\Delta \mathrm{G}_{\mathrm{D} 3}\right)$ calculated for the formation of the $\mathrm{ZH}-\mathrm{R}$ adducts are larger than $-40 \mathrm{kcal} / \mathrm{mol}$ in the 10-ring channels of MFI and MWW structures, around $-38 \mathrm{kcal} / \mathrm{mol}$ at the channels intersections of MFI and 12-ring channels of MOR, and less important, -29 $\mathrm{kcal} / \mathrm{mol}$, at the external hemi-cavities of MWW zeolites. Formation of the $\mathrm{RH}^{+}$cation from adsorbed ethylbenzene, that is, the $\mathrm{ZH}-\mathrm{R} \rightarrow \mathrm{Z}^{-} \mathrm{RH}^{+}$process, is endothermic in all cases, and the stability of the resulting system depends on the location of the Brönsted acid site. Thus, the carbonium ion is unstable within the 10-ring pores of the MWW framework and in the sinusoidal 10ring channels of MFI, and deprotonates spontaneously regenerating the neutral reactant system. In these materials, it is only possible to optimize the carbonium ion in some particular orientations in which the positive charge is far from the $\mathrm{Al}$ atom and the directly connected oxygen atoms, resulting in a low stabilization of protonated ethylbenzene (see Figures 2A and S2A, and optimized $\mathrm{r}(\mathrm{H}-\mathrm{Al})$ distances in Table 1). In contrast, it is possible to protonate ethylbenzene and to form a relatively stable $\mathrm{Z}^{-} \mathrm{RH}^{+}$ion pair in the 12-ring channels of MOR (Figure S1), in the channels intersection of MFI (Figure S2B) and within the hemi-cavities opened to the external surface of the MWW structure (Figure 2B). A deeper analysis of the dispersion corrections (D3 values) summarized in Table S1 reveals that the contribution of dispersion interactions to the stability of the confined species does not change much along the reaction when the reactant and intermediate species are located 
inside the microporous channel system (for instance, $-6 \mathrm{kcal} / \mathrm{mol}$ in MWW-10R, $+4 \mathrm{kcal} / \mathrm{mol}$ in MFI-str, see Table S1). But the situation is different in the external "cups" of the MWW structure, where the D3 correction increases from $-23.8 \mathrm{kcal} / \mathrm{mol}$ in adsorbed ethylbenzene to $-41.9 \mathrm{kcal} / \mathrm{mol}$ in the ionic $\mathrm{Z}^{-} \mathrm{RH}^{+}$intermediate. This is because in the reactant system ZH-R, part of the aromatic ring is not inside the hemi-cavities, and therefore it is not stabilized by interactions with the zeolite framework (Figure 2B). In contrast, the carbonium ion (and the transition state for its formation, see Figure S3) is fully surrounded by framework oxygen atoms, so that dispersion interactions are maximized and become comparable to those present within the channel system $(-41.9 \mathrm{vs}-46.3 \mathrm{kcal} / \mathrm{mol})$. Thus, ethylbenzene disproportionation following the ethyl-transfer mechanism is feasible in the 12-ring pores of MOR, in the channels' intersection of MFI and in the external 12-ring "cups" of MWW, and will not take place easily within the 10-ring channels of MFI or MWW.
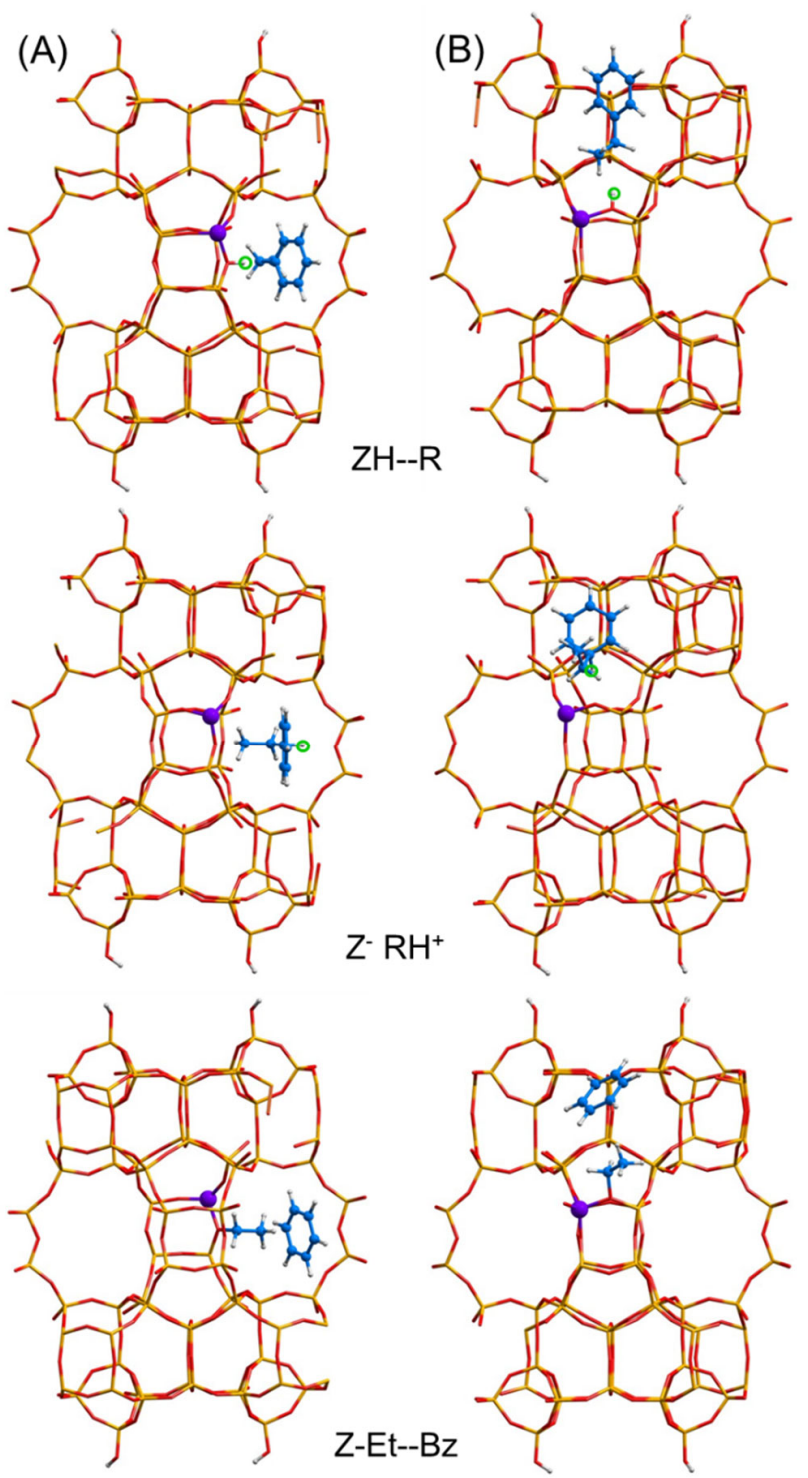

Figure 2. Optimized structures of the intermediates involved in the alkyl-transfer pathway in (A) 10-ring pores and (B) external cups of MWW. Si and $\mathrm{O}$ atoms are depicted as yellow and red sticks. Al, $\mathrm{C}$ and $\mathrm{H}$ atoms are depicted as purple, blue and white balls. The green circle highlights the proton.
Table 1. Relative stability of species involved in the alkyl-transfer pathway referred to ethylbenzene plus Brönsted acid site in different zeolites, and reaction energy for ethylbenzene protonation. Dispersion-corrected Gibbs free energies at $573 \mathrm{~K}$ $\left(\Delta \mathrm{G}_{\mathrm{D} 3}\right)$ are given in $\mathrm{kcal} / \mathrm{mol}$. Distances between the $\mathrm{H}^{+}$and the $\mathrm{Al}$ center in the $\mathrm{Z}^{-} \mathrm{RH}^{+}$systems $(\mathrm{r}(\mathrm{H}-\mathrm{Al}))$ are given in $\AA$.

\begin{tabular}{cccccc}
\hline & ZH--R & Z- RH $^{+}$ & Z-Et--Bz & r(H-Al) & $\begin{array}{c}\text { ZH-R } \rightarrow \\
\text { Z- RH }^{+}\end{array}$ \\
\hline MOR-12R & -37.8 & -20.8 & -30.0 & 2.795 & 17.0 \\
MFI-str & -46.2 & -24.2 & -33.5 & 4.795 & 22.0 \\
MFI-sin & -42.7 & -15.1 & -32.8 & 7.261 & 27.6 \\
MFI-int & -38.6 & -28.1 & -37.6 & 4.836 & 10.6 \\
MWW-10R & -40.1 & -10.8 & -30.2 & 8.951 & 29.3 \\
MWW-cup & -28.7 & -19.2 & -20.2 & 3.100 & 9.5 \\
\hline
\end{tabular}

The initiation step in the diaryl-mediated pathway (Scheme 2B) involves abstraction of a hydride from the alkyl group of the reactant generating a carbenium ion $\mathrm{R}^{+}$that then enters the true catalytic cycle by reacting with a second alkylaromatic molecule and forming a cationic diaryl intermediate $\mathrm{I}^{+}$. An intramolecular proton transfer to the other ring generates a different diaryl intermediate $\mathrm{I}^{+}$that decomposes into benzene and a dialkyl carbenium ion $\mathrm{P}^{+}$. Finally, hydride transfer from a new reactant molecule yields the neutral dialkyl-aromatic product and a new $\mathrm{R}^{+}$ carbenium ion that directly enters the catalytic cycle without the need of a new and slow hydride abstraction as initiation step.

The activation energies reported for the initial hydride abstraction step on a Brönsted acid site are really high, $\sim 50 \mathrm{kcal} / \mathrm{mol} .^{14-16}$ However, it was proposed by different groups that $\mathrm{La}^{3+}$ cations present in $\mathrm{HLaX}^{45} \mathrm{HLaY}^{46}$ or LaNaY zeolites, ${ }^{32}$ as well as extraframework Al species acting as Lewis acid sites in $\mathrm{HX}$ and $\mathrm{HY},{ }^{19,20}$ are able to activate the $\mathrm{C}-\mathrm{H}$ bond in alkanes and form carbenium ions via hydride abstraction at lower temperatures. As regards the cationic nature of the $\mathrm{R}^{+}$species, it should be noticed that while primary carbenium ions only exist as alkoxide intermediates covalently bound to framework oxygen atoms, the secondary ethylbenzenium cation $\mathrm{R}^{+}$exists as a stable ionic species in all zeolite structures and local environments considered, being less than $5 \mathrm{kcal} / \mathrm{mol}$ higher in energy than the corresponding alkoxide counterpart (see Table S2 and Figure S4). Therefore, since carbenium ions $\mathrm{R}^{+}$exist as stable species inside the zeolite channels and cavities irrespective of the Al location, and with the objective of accurately quantifying the influence of confinement effects associated only to the fitting of the organic intermediates with the pore dimensions and architecture, the aryl-mediated pathway was investigated using a pure silica zeolite model and considering ethylbenzenium cation $\mathrm{R}^{+}$and ethylbenzene $\mathrm{R}$ as the initial reactant species. In this way, the possibility to obtain small energy differences associated to the relative location of the organic fragments and the Al centers is discarded, and only the influence of confinement effects is evaluated.

Within the true catalytic cycle, a two-step pathway has been usually assumed to convert $\mathrm{I}^{+}$into $\mathrm{I}^{+}$, which involves a proton transfer from $\mathrm{I}^{+}$to the zeolite framework generating a neutral intermediate (I in Scheme 2) that is subsequently protonated in the other ring to yield $\mathrm{I}^{+}$. The activation energies previously reported for this step in TON and FAU structures are $16-18 \mathrm{kcal} / \mathrm{mol}^{14-16}$ much lower than the initial hydride abstraction. Now, we have explored other pathways that only involve intramolecular $\mathrm{H}$-shifts within the 
cationic intermediates and don't require the direct participation of the zeolite framework. It is possible to directly transfer the proton from one aryl group to the other through a four-membered transition state (TS12 in Figure S5), but the activation energy necessary is high because of the forced geometry of the system. However, there is an alternative pathway in which the $\mathrm{H}$ atom in $\mathrm{I}^{+}$shifts first to the $\mathrm{C}$ atom in alfa position to form $\mathrm{I}^{+}$intermediate and then, through a less constrained six-membered transition state (TS34 in Figure S5) is easily transferred to the second aryl group. In this three-step pathway all calculated activation energies are lower than $13 \mathrm{kcal} / \mathrm{mol}$ (see Figure S6), and the geometrical conformation of all the diaryl intermediates and transition states is nearly equivalent. Therefore, the species considered to assess the viability of the diaryl-mediated mechanism in each of the zeolite frameworks investigated are the deprotonated carbenium ion $\mathrm{R}^{+}$ stabilized by a close ethylbenzene molecule $\mathrm{R}\left(\mathrm{R}^{+}-\mathrm{R}\right.$ complex), the cationic diaryl intermediates $\mathrm{I}^{+}$and $\mathrm{I}^{+}$, the diethyl-carbenium ion $\mathrm{P}^{+}$in close proximity with the resulting $\mathrm{Bz}$ product $(\mathrm{P}--\mathrm{Bz}$ complex) (see Scheme 2B).
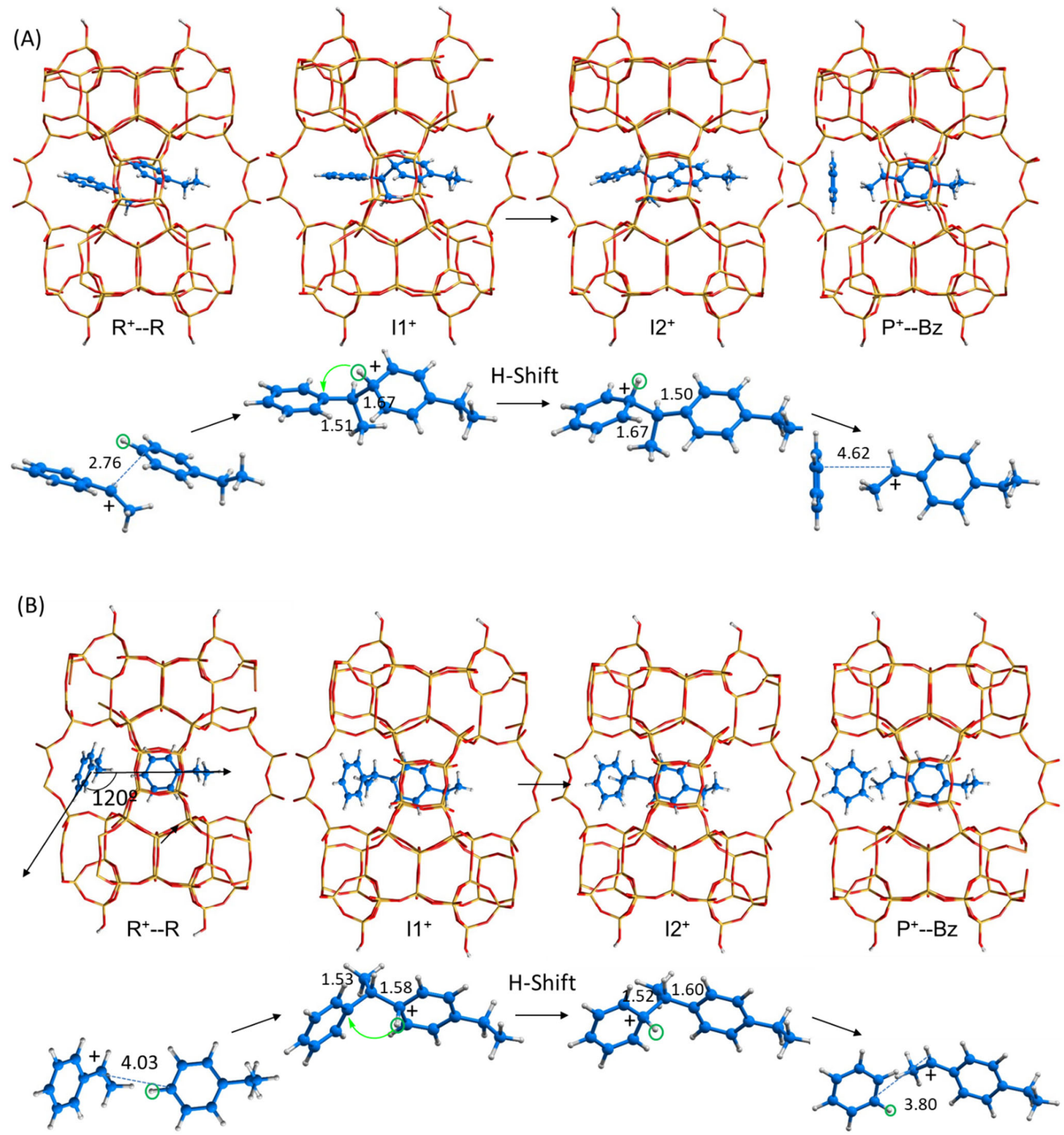

Figure 3. Optimized structures of the intermediates involved in the diaryl-mediated pathway in the 10-ring channels of MWW with different orientation of reactants: (A) parallel and (B) bent. C-C distances in $\AA$. 
Table 2. Relative stability of the intermediates involved in the diaryl-mediated disproportionation pathway referred to adsorbed ethylbenzenium carbenium ion $\mathrm{R}^{+}$and non-adsorbed ethylbenzene. Dispersion-corrected Gibbs free energies at $573 \mathrm{~K}\left(\Delta \mathrm{G}_{\mathrm{D} 3}\right)$ are given in $\mathrm{kcal} / \mathrm{mol}$.

\begin{tabular}{ccccc}
\hline & $\mathrm{R}^{+}-\mathrm{R}$ & $\mathrm{I}^{+}$ & $\mathrm{I}^{+}$ & $\mathrm{P}^{+}--\mathrm{Bz}$ \\
\hline MOR-12R & -46.5 & -41.2 & - & -48.1 \\
MFI-str & -34.3 & -39.8 & -55.0 & -52.2 \\
MFI-sin & -42.4 & -38.9 & -28.0 & -48.0 \\
MFI-int & -42.9 & -33.1 & -54.9 & -67.8 \\
MWW-10R & -45.2 & -32.0 & -24.9 & -68.3 \\
MWW-10R\| & -50.2 & -26.7 & -32.1 & -52.8 \\
MWW-cup & -27.2 & -17.8 & -10.1 & -23.4 \\
\hline
\end{tabular}

Data in Table 2 show that the bimolecular pathway is not restricted in the large 12-ring pores of MOR. Reactants and products are able to diffuse through the channels, the carbenium ion $\mathrm{R}^{+}$can approach another ethylbenzene molecule forming a stable complex $\left(\mathrm{R}^{+}-\mathrm{R}\right.$ in Figure S7) in which the $\mathrm{C}^{+}-\mathrm{C}$ distance is $2.577 \AA$, and the geometry of the subsequent diaryl intermediate $\mathrm{I}^{+}$and products can be easily accomodated, resulting in an almost thermoneutral process. Notice that in MOR the $\mathrm{I}^{+}$intermediate is not stable, and the intramolecular $\mathrm{H}$-shift and the $\mathrm{C}-\mathrm{C}$ bond dissociation occur simultaneously, directly producing the diethylbenzene $\mathrm{P}^{+}$cation (Figure S7). The sinusoidal 10-ring channel of the MWW structure allows the location of the initial ethylbenzenium cation $\mathrm{R}^{+}$and a neutral ethylbenzene molecule $\mathrm{R}$ in at least two different orientations. The two species can be placed nearly parallel within the 10-ring channel, in a similar orientation as in MOR, and with an optimized $\mathrm{C}^{+}-\mathrm{C}$ distance of $2.764 \AA$ (Figure $3 \mathrm{~A}$ and entry MWW-10R $\|$ in Table 2), or they can be more separated within the 10-ring channels (Figure 3B and entry MWW-10R in Table 2), with a $\mathrm{C}^{+}-\mathrm{C}$ distance of $4.034 \AA$ and with the molecular axis of the two reactant fragments forming an angle of $\sim 120^{\circ}$. The bent orientation is $5 \mathrm{kcal} / \mathrm{mol}$ less stable than the parallel one, but the formation of the $\mathrm{I}^{+}$intermediate, the subsequent $\mathrm{H}$-shift leading to $\mathrm{I}^{+}$species and the final $\mathrm{C}-\mathrm{C}$ bond breaking producing $\mathrm{DEB}^{+}$carbenium ion are similarly favorable in both cases. In contrast, the bimolecular process is more difficult in the "cups" of the MWW external surface due to a lack of stabilization by dispersion interactions of the ethylbenzene molecule that should react with the initially adsorbed ethylbenzenium cation (see Tables 2 and S3, and optimized structures in Figure 4), despite the viability of the process from the geometric point of view.

The unexpected finding that formation of bulky diaryl intermediates is disfavored at the "cups" of the external surface of MCM-22 and of ITQ-2 layers, with less spatial restrictions than inside the channels, stresses the importance of dispersion interactions in zeolite catalysis. Indeed, if the dispersion correction term D3 is not included in the calculations, formation of the $\mathrm{R}^{+}-\mathrm{R}$ complex is favorable in the external "cups" $(\Delta \mathrm{G}=-24.9 \mathrm{kcal} / \mathrm{mol})$ but not within the 10-ring channels $(\Delta \mathrm{G}>0)$, and the same trend is found for the whole process. However, when dispersion corrections are included the trend is reversed, and the calculated $\Delta \mathrm{G}_{\mathrm{D} 3}$ values confirm that the diaryl-mediated pathway is energetically favored within the 10-ring channels of MWW. It should be noted at this point that the same argument of lack confinement at the external "cups" of MWW zeolites should be used to discuss the viability of the alkyl-transfer pathway. To this end we have calculated the adsorption of a second ethylbenzene molecule close to an ethoxy group placed inside one of the external hemi-cavities, and we have found that in this case ethylbenzene is able to get into the hemicavity, so that the contribution of dispersion interactions is large (D3 $=-19.7 \mathrm{kcal} / \mathrm{mol}$, see Table S4) and the process is energetically viable.
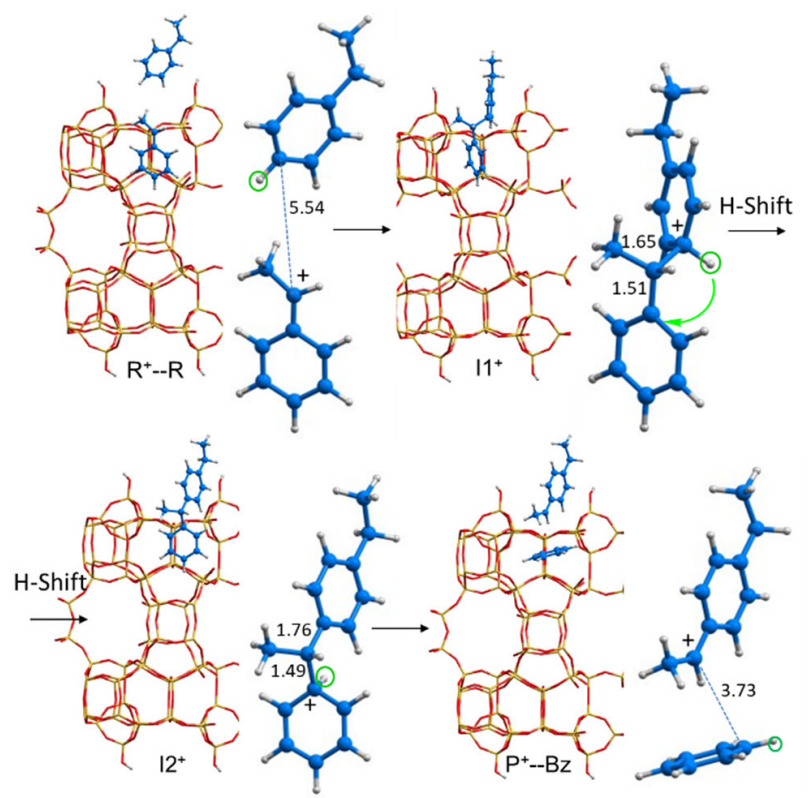

Figure 4. Optimized structures of the intermediates involved in the diaryl-mediated pathway in the external MWW hemi-cavities. C-C distances in $\AA$.

(A)

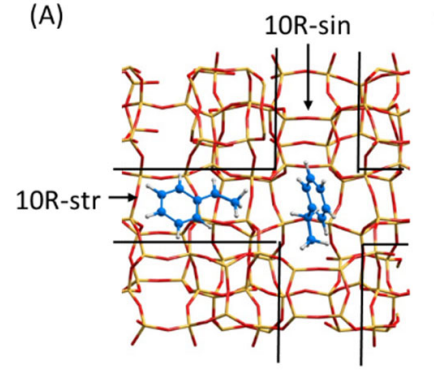

(B)

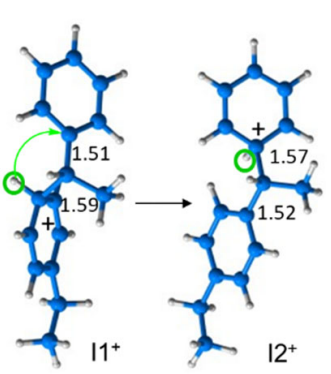

(C)

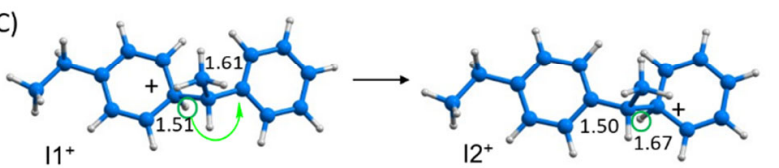

(D)

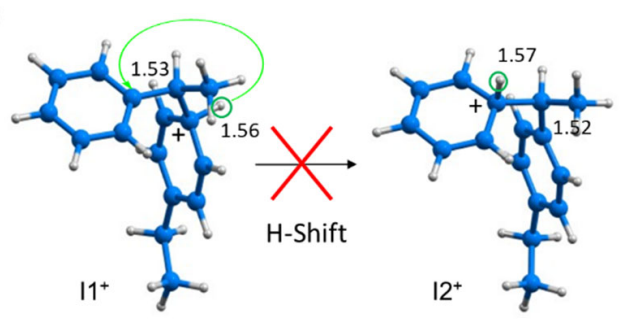

Figure 5. Optimized structure of the $\mathrm{R}^{+}-\mathrm{R}$ reactant system involved in the diaryl-mediated pathway in the channels' intersection of MFI (A) and of the diaryl intermediates $\mathrm{I}^{+}$and $\mathrm{I}^{+}$ in the sinusoidal (B) and straight (C) channels, and at the channels' intersection of MFI (D). C-C distances in $\AA$. 
The diaryl-mediated pathway could in principle proceed also within the microporous structure of MFI when both ethylbenzenium cation $\mathrm{R}^{+}$and ethylbenzene are close and parallel in the same 10-ring channel, either the straight one (Figures $5 \mathrm{C}$ and S8A) or the sinusoidal one (Figure 5B and S8B). In both cases the formation of the diaryl intermediate $\mathrm{I}^{+}$is nearly thermoneutral, and the subsequent $\mathrm{H}$-shift producing $\mathrm{I}^{+}$is geometrically possible and energetically accessible (Table 2). However, when each of the reactant fragments is diffusing along a different channel, the orientation in which they approach to each other, forming an angle of $\sim 90^{\circ}$, makes the proton transfer highly improbable. As depicted in detail in Figure 5D, in the $\mathrm{I}^{+}$intermediate formed at the channels intersection in MFI, the proton that has to be transferred to the other aryl ring is not pointing to such ring as it happens in all other intermediates obtained in this work, but it is oriented in the opposite direction. This means that the proton shift process would require a previous rotation of the diaryl intermediate (either protonated or neutral, see Scheme 2) in order to occur. But this rotation is highly impeded in MFI, where the ethylbenzene fragments are confined along the 10-ring channels and there is no place for such large intermediates to change their orientation. As a consequence, the proton shift does not take place and the diethylbenzene product is not formed, but the cationic diaryl intermediate may remain blocked at the channels intersection leading to catalyst deactivation.

In summary, the DFT results indicate that diaryl-mediated disproportionation mechanism is viable in the 12-ring channels of MOR and within the intralayer 10-ring channels of the MWW structure, and less favored in MFI and at the external hemi-cavities of MCM-22 and ITQ-2. In contrast, the alkyl-transfer pathway is energetically feasible in MOR, at the external "cups" of MWW zeolites, and at the channels intersections of MFI, unless these voids become blocked by diaryl intermediates. Thus, the architecture of the channel systems and the orientation and stabilization by dispersion forces of the species involved in each of the steps will determine the activity and the selectivity of the ethylbenzene disproportionation in medium pore zeolites.

2.2. Catalytic study. The four zeolites studied by DFT calculations have been used as acid catalysts for the conversion of ethylbenzene. In order to minimize as much as possible the influence of parameters others than crystalline structure, zeolites mordenite, ZSM-5 and DS-ITQ-2 used have comparable molar Si/Al ratios, in the range of 11-14. The MCM-22 chosen has a lower $\mathrm{Si} / \mathrm{Al}$ ratio of 24 with the aim of matching its activity with that of the bidimensional MWW zeolite. The rest of physico-chemical properties of the samples compared are summarized in the Supporting Information (see Table S5).

The ethylbenzene conversion obtained with ZSM-5, mordenite, MCM-22 and DS-ITQ-2, at increasing contact times and $573 \mathrm{~K}$, is shown in Figure 6A. Under these conditions, ethylbenzene disproportionation following the diaryl-mediated pathway is expected to prevail over the alkyl-transfer mechanism and the associated dealkylation, since the initial protonation of ethylbenzene to form a carbonium ion is energetically demanding and requires higher temperatures to occur. Indeed, the yield of gases (mostly ethene) obtained at $573 \mathrm{~K}$ is below $1 \%$ in the four catalysts (see Figure S11 and S12), indicating that dealkylation is not relevant under these conditions. Mordenite presents the highest activity. This is not surprising, as the diaryl-mediated disproportionation is energetically viable in the 12-ring channels of
MOR according to the theoretical results presented above. DS-ITQ2 and MCM-22 give similar ethylbenzene conversion, lower than that of the large pore mordenite, and in line with their respective Brönsted acid site density (see Table S5). The large differences in the external surface area $\left(\mathrm{S}_{\mathrm{ext}}\right)$ and, therefore, in the number of accessible "cups" between DS-ITQ-2 and MCM-22 does not affect the ethylbenzene conversion significantly under these conditions, suggesting that the contribution of the external hemi-cavities to the conversion of ethylbenzene following the diaryl-mediated mechanism is only minor at $573 \mathrm{~K}$ and, consequently, that disproportionation should take place mainly within the intra-layer 10-ring channels of these two zeolites, as was predicted by the theoretical calculations. Finally, ZSM-5 is significantly less active as compared to the two medium pore MWW zeolites, in good agreement with the theoretical results that evidenced the diarylmediated pathway to be disfavored within the MFI structure, and with earlier studies that proposed the reaction to proceed through dealkylation and later realkylation in the MFI zeolite. ${ }^{21,}{ }^{35}$ More recently, Huang et al. have presented NMR spectroscopic evidences for the ethyl-transfer reaction pathway to prevail on ZSM-5. ${ }^{19}$
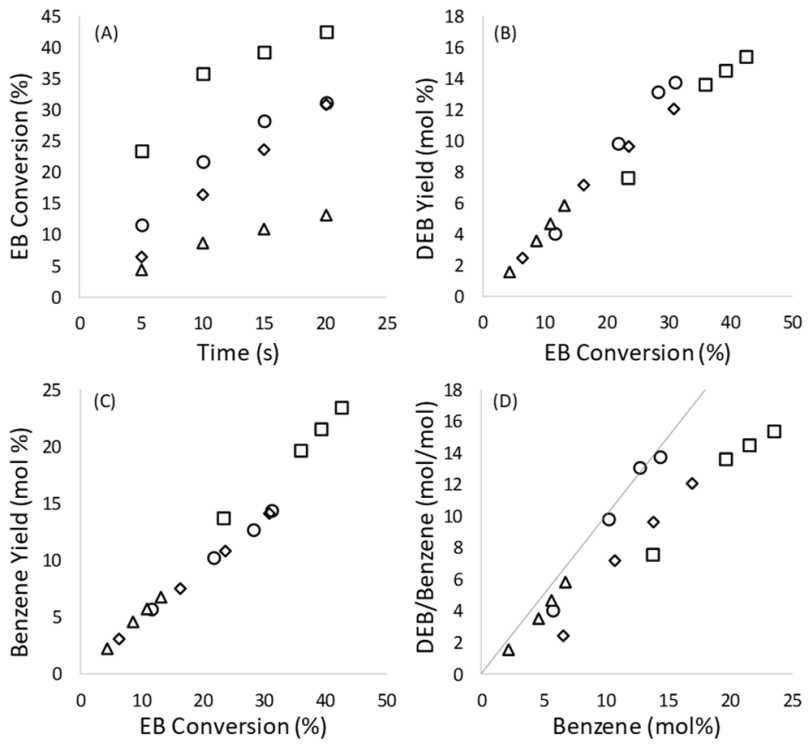

Figure 6. Ethylbenzene conversion (A), DEB selectivity (B), benzene selectivity $(\mathrm{C})$ and $\mathrm{DEB} /$ benzene molar ratio (D) for DSITQ-2 (०), mordenite ( $\square)$, ZSM-5 $(\Delta)$ and MCM-22 $(\diamond)$. T=573 K, contact time $=5-20 \mathrm{~s}$.

According to the product distribution plotted in Figure 6B-D, DSITQ-2 is very selective to diethylbenzene, even at ethylbenzene conversions above $20 \%$. The DEB/benzene molar ratio obtained with the bi-dimensional zeolite, close to one, indicates that stoichiometric disproportionation is prevailing under these conditions, while MCM-22 and the large pore mordenite yield less diethylbenzene. From previous catalytic studies, it is generally accepted that disproportionation of alkylaromatics catalyzed by large pore zeolites, such as mordenite, proceeds through the formation of diaryl intermediates. ${ }^{35,47}$ Higher alkylated aromatics are also formed inside large pore zeolites, ${ }^{35,47}$ and in medium pore zeolite structures containing cavities, ${ }^{17}$ leading to an induction period wherein benzene is present in higher proportion than diethylbenzene within the products. This is, indeed, what can be deduced from Figures $6 \mathrm{~B}$ and $6 \mathrm{D}$. Mordenite presents the lowest selectivity to $\mathrm{DEB}$ and the lowest $\mathrm{DEB} /$ benzene molar ratio, 
followed by MCM-22. In the case of the latter, the DEB deficit can be due to the conversion of DEB to bulkier alkylaromatics by means of consecutive disproportionation reactions within the supercages of MCM-22, cages that are less abundant in the DSITQ-2 sample. In fact, diaryl-intermediates have been detected in the 12-ring cages of MCM-22, ${ }^{17}$ but they will hardly diffuse out of these cages through the 10-ring windows, thus blocking the cavities and leading to fast catalyst deactivation. ${ }^{19}$ A similar behavior was also observed for disproportionation of $m$-xylene. ${ }^{22,23}$

Regarding the selectivity within the DEB fraction, Figure 7 shows that mordenite is not $p$-selective, as could be expected from its large pore structure, ${ }^{31,48}$ and that the highest $p / o$-DEB ratio is obtained for the medium pore ZSM-5 (Figure 7A). However, due to the low yield to of the $o$-isomer, not only in the presence of medium pore but also of large pore zeolites, ${ }^{47}$ the $p / m$-DEB ratio can been used to provide more reliable information regarding the relative contribution of the internal and external active sites. Previous studies have shown that $p$-DEB is the primary disproportionation product, whereas $m$-DEB is formed by secondary isomerization, either within the channels or cavities in the case of large pore zeolites, or at external acid sites in medium pore zeolites, such as ZSM-5 or MCM-22. ${ }^{47,49,50}$ The low $p / m$-DEB ratio observed for ZSM-5 at $573 \mathrm{~K}$ (see Figure 7B) suggests that the small fraction of ethylbenzene converted at this temperature occurs mainly on active sites close to the external surface of the crystals. In the case of the two catalysts with the MWW structure, the bi-dimensional DSITQ-2 presents lower $p / m$-DEB ratio when compared to MCM-22. The larger external surface area and the higher amount of "cups" accessible on the bi-dimensional zeolite may contribute to some extent to the conversion of ethylbenzene by means of the alkyltransfer pathway, but may also enhance the isomerization of the $p$ DEB to the $m$ - isomer, thermodynamically favored.

Experiments have also been performed at higher temperatures, in order to enhance the contribution of the alkyl-transfer mechanism to the total conversion of ethylbenzene. The activity of the different catalysts at 623 and $673 \mathrm{~K}$ is presented in Figures S10 and 8A. Mordenite is the most active catalyst in all cases but, as reaction temperature is increased, the ethylbenzene conversion obtained with ZSM-5 comes closer to that of the MWW catalysts. The results agree with the theoretical data obtained for the medium pore ZSM-5, which evidenced the viability of ethylbenzene disproportionation following the alkyl-transfer pathway in the channel intersections of the MFI structure. MCM-22 and DS-ITQ2 present comparable ethylbenzene conversion, slightly higher for the layered zeolite, following the same trend as at $573 \mathrm{~K}$.
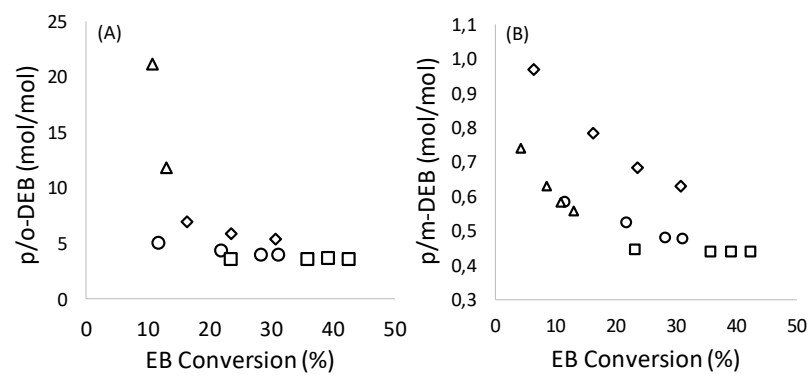

Figure 7. $p / \mathrm{o}-\mathrm{DEB}(\mathrm{A})$ and $p / m$-DEB (B) molar ratios obtained for DS-ITQ-2 (०), mordenite ( $\square)$, ZSM-5 $(\Delta)$ and MCM-22 $(\diamond)$. T=573 $\mathrm{K}$, contact time $=5-20 \mathrm{~s}$.
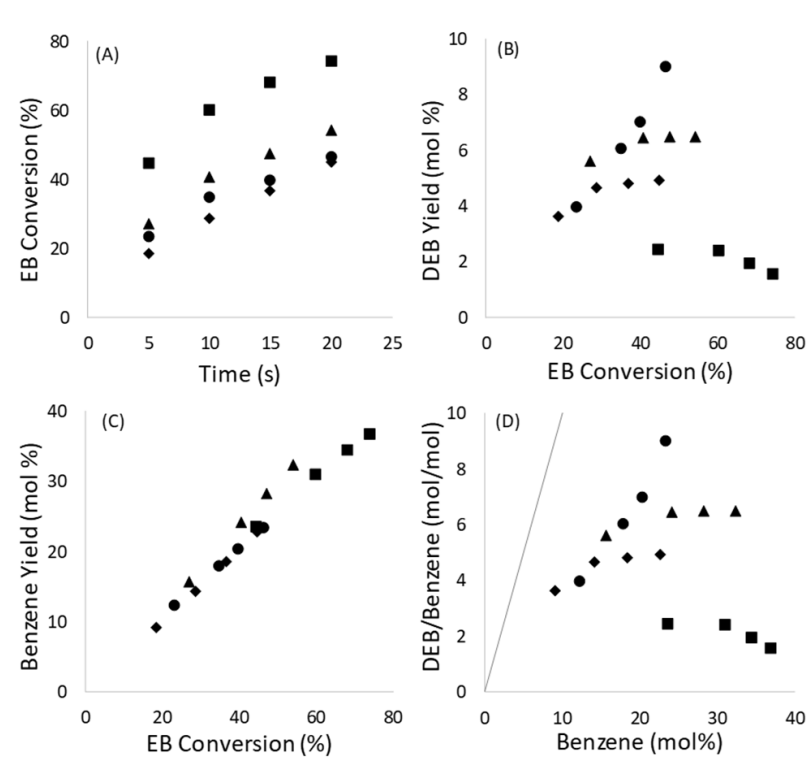

Figure 8. Ethylbenzene conversion (A), DEB selectivity (B), benzene selectivity $(\mathrm{C})$ and $\mathrm{DEB} /$ benzene molar ratio (D) for DSITQ-2 (•), mordenite (•), ZSM-5 ( $\bullet$ ) and MCM-22 (•). T=673 K, contact time $=5-20 \mathrm{~s}$.
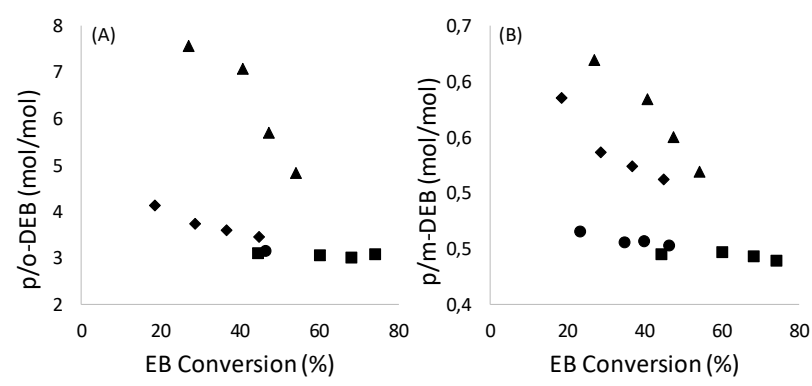

Figure 9. $p / 0-D E B(A)$ and $p / m$-DEB (B) molar ratios obtained for

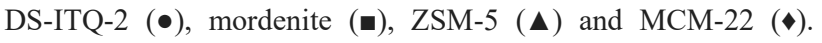
$\mathrm{T}=673 \mathrm{~K}$, contact time $=5-20 \mathrm{~s}$.

At $673 \mathrm{~K}$ the DEB/benzene molar ratio is below 1 for all the zeolites studied, due to a larger contribution of ethylbenzene dealkylation at this higher temperature (see Figure 8D). In fact, the decrease in DEB yield is accompanied by an increase in the fraction of gaseous products in all cases (see Figures S11 and S12). Nevertheless, the layered DS-ITQ-2 zeolite is still the most selective to DEB. The lower ethylbenzene dealkylation capacity of DS-ITQ-2 as compared to MCM-22 can be explained by the higher contribution of the external 12-ring hemi-cavities to the conversion of ethylbenzene. Within these "cups" ethylbenzene can disproportionate following the alkyl-transfer mechanism, as predicted by the theoretical calculations, and the particular stabilization of a second ethylbenzene molecule approaching the ethoxy group formed in the hemi-cavity will allow the formation of DEB instead of the competing desorption of ethylene. The DEBs formed on the external "cups" will isomerize to their equilibrium distribution, reducing the levels of $p$-selectivity of the layered DSITQ-2 zeolite to values comparable to those of the large pore mordenite (see Figure 9). In the case of MCM-22, the DEBs formed within the supercages will not be able to diffuse out through the 10ring windows resulting in a lower DEB yield, while in ZSM-5 and mordenite de-ethylation is more favored, and selectivity to DEB is lower than for the layered DS-ITQ-2. 
Thus, the experimental results have shown that the large pore mordenite is highly active for ethylbenzene conversion, but with a low selectivity to DEB at high temperature, while the medium pore ZSM-5 is able to convert ethylbenzene only at temperatures high enough to enable the reaction to proceed following the alkyltransfer mechanism. Under those conditions, dealkylation competes with disproportionation reducing the overall selectivity to DEB. When the experiments are performed at $573 \mathrm{~K}$, which is a reaction temperature too low for dealkylation to contribute in a significant proportion, the bi-dimensional DS-ITQ-2 is more active than a medium pore ZSM-5 with comparable acidity and it is more selective to DEB than mordenite, ZSM-5 or even a MCM-22 of comparable activity. The sinusoidal 10-ring channel system, present in the layers of DS-ITQ-2 zeolite and in MCM-22, is active for ethylbenzene disproportionation following the aryl-mediated pathway, and therefore highly selective to DEB. At higher reaction temperature, the external "cups" of the MWW zeolites will also contribute to the selective conversion of ethylbenzene by means of the alkyl-transfer mechanism. The pore system formed by the 12ring cavities present in MCM-22 is responsible for a reduction of DEB selectivity due to secondary conversion of this primary product to bulkier alkylaromatics, which are not able to egress from the supercages, leading to a larger proportion of light gases and benzene in the final product mixture.

\section{CONCLUSIONS}

The contribution of the different channel systems of three medium pore zeolites, MCM-22, DS-ITQ-2 and ZSM-5, and of a large pore mordenite zeolite to the conversion of ethylbenzene has been unraveled by a combination of DFT calculations including dispersion interactions and catalytic results obtained at short contact times. The DFT study indicates that the diaryl-mediated ethylbenzene disproportionation mechanism is energetically affordable, not only in the 12-ring channels of MOR, but also within the intra-layer 10-ring channels of the MWW structure, while it is not so relevant at the external "cups" of MCM-22 and DS-ITQ-2 due to the lack of confinement. In contrast, the alkyltransfer pathway is energetically preferred at the external cups of DS-ITQ-2 and at the channels intersections of ZSM-5. In good agreement with the theoretical results, when the reaction is performed at $573 \mathrm{~K}$, conditions under which the diaryl-mediated disproportionation mechanism prevails and the contribution of the alkyl-transfer pathway is only minor, ZSM-5 presents significantly lower activity than a DS-ITQ-2 zeolite with comparable Si/Al ratio. Moreover, DS-ITQ-2 and MCM-22 present comparable ethylbenzene conversion, confirming that the disproportionation takes place mainly in the 10-ring channels of these two zeolites and that the external "cups", much more abundant in the bi-dimensional material, do not play a significant role under these low temperature conditions. At higher reaction temperatures the alkyl-transfer mechanism starts contributing to the conversion of ethylbenzene and, consequently, the activity of ZSM-5 increases to values close to those of DS-ITQ-2 or MCM-22, although the selectivity to DEB decreases at high conversion due to competing ethylbenzene dealkylation. In MCM-22, the pore system formed by the 12-ring cavities, responsible for the secondary conversion of DEB to bulkier alkylaromatics which are not able to egress from the supercages, results in a lower selectivity to DEB at 623-673 K. In contrast, in DS-ITQ-2, part of the ethylbenzene is selectively converted to DEB by means of the ethyl-transfer mechanism in the external "cups" of the layered material. Altogether, DS-ITQ-2 presents the highest selectivity to DEB, independently of the reaction temperature.

\section{EXPERIMENTAL SECTION}

4.1. Computational Details. All calculations are based on periodic density functional theory (DFT) and were performed using the Perdew-Wang (PW91) exchange-correlation functional within the generalized gradient approach $(\mathrm{GGA})^{51,52}$ as implemented in the Vienna Ab-initio Simulation Package (VASP) code. ${ }^{53}$ The valence density was expanded in a plane wave basis set with a kinetic energy cutoff of $500 \mathrm{eV}$, and the effect of the core electrons in the valence density was taken into account by means of the projected augmented wave (PAW) formalism. ${ }^{54}$ Integration in the reciprocal space was carried out at the $\Gamma$ k-point of the Brillouin zone. During geometry minimizations, the positions of all atoms in the systems were fully relaxed without any restriction. Dispersion corrections to the energies were evaluated using the D3 Grimme's method. ${ }^{55,56}$ Absolute Gibbs free energies of all species are given by:

$$
\mathrm{G}=\mathrm{E}_{\text {tot }}+\mathrm{E}_{\mathrm{ZPE}}+\mathrm{E}_{\mathrm{vib}}-\mathrm{TS}_{\mathrm{vib}}
$$

where $E_{\text {tot }}$ is the electronic energy obtained from the DFT calculation, EZPE is the zero point energy correction, $E_{v i b}$ is the vibrational thermal energy contribution and $\mathrm{S}_{\mathrm{vib}}$ is the vibrational entropy. The vibrational contributions to the energy and entropy were calculated according to

$$
\begin{gathered}
E_{Z P E}=\sum_{i=1}^{3 N-6} \frac{1}{2} h v_{i} \\
E_{v i b}=R \sum_{i=1}^{3 N-6} \frac{h v_{i}}{k_{B}\left(e^{h v_{i} / k_{B} T}-1\right)} \\
S_{v i b}=R \sum_{i=1}^{3 N-6} \frac{h v_{i}}{k_{B}\left(e^{h v_{i} / k_{B} T}-1\right)}-\ln \left(1-e^{h v_{i} / k_{B} T}\right)
\end{gathered}
$$

using the vibrational frequencies $v$ obtained from the DFT calculations.

Different models were used to study the alkyl-transfer and the diaryl-mediated disproportionation mechanisms. In the first case, a zeolite model containing one $\mathrm{Al}$ atom and the associated Brönsted acid site was employed to simulate the catalyst and its reaction with ethylbenzene, so that the total charge of the system was always zero. In the second case, the zeolite was simulated by a neutral pure silica model in which the neutral ethylbenzene and the charged ethylbenzenium cation react. In this situation, the total charge of the system was always one.

MWW crystallizes in a hexagonal $\mathrm{P} 6 / \mathrm{mmm}$ space group with lattice parameters $\mathrm{a}=\mathrm{b}=14.390$ and $\mathrm{c}=25.198 \AA$, and contains 216 atoms in the conventional unit cell $(72 \mathrm{~T}$ and $144 \mathrm{O})$. The MWW silicon framework is composed of four-, five- and sixmembered rings that link to form two independent channel systems, a bidimensional sinusoidal 10-ring channel system (4.1 x $5.1 \AA$ ) running within the layers, and a second one formed by twelvemembered ring supercages $(7.1 \times 7.1 \times 18.2 \AA)$ interconnected by 10 -ring pores. A model for delaminated ITQ- 2 zeolite was created by hydrolyzing the two $\mathrm{Si}-\mathrm{O}-\mathrm{Si}$ bonds per unit cell linking the layers, and by expanding the lattice along $\mathrm{c}$ to a final value of $\mathrm{c}=$ $35.216 \AA$ (Figure 1). Among the eight non-equivalent tetrahedral sites in the MWW unit cell, Al was placed at $\mathrm{T} 8$ to generate a 
Brönsted acid site accessible from both the 10-ring channel and the external hemi-cavities.

MFI crystallizes in an orthorhombic Pnma space group with lattice parameters $\mathrm{a}=20.090, \mathrm{~b}=19.738$ and $\mathrm{c}=13.142 \AA$, and contains 288 atoms ( $96 \mathrm{~T}$ and $192 \mathrm{O}$ ) in the conventional unit cell. The MFI framework is composed of four-, five- and six-membered rings that link to form ten-membered ring channels. The 3D channel system of MFI is composed by straight 10-ring channels along b (of $5.3 \mathrm{x}$ $5.6 \AA)$ interconnected with sinusoidal 10-ring channels perpendicular to b (of $5.1 \times 5.5 \AA$ ) (Figure 1). Among the twelve non-equivalent tetrahedral sites in the MFI unit cell, only T4, T7, $\mathrm{T} 8$ and $\mathrm{T} 11$ are in the 10-ring channels, and the rest (T1, T2, T3, $\mathrm{T} 5, \mathrm{~T} 6, \mathrm{~T} 9, \mathrm{~T} 10$ and $\mathrm{T} 12$ ) are at the channels intersection. The Brönsted acid site was generated by placing an $\mathrm{Al}$ atom at $\mathrm{T} 1$ site, which is accessible from all 10-ring channels.

Mordenite crystallizes in an orthorhombic $\mathrm{Cmcm}$ space group with lattice parameters $\mathrm{a}=18.094, \mathrm{~b}=20.516$ and $\mathrm{c}=7.524 \AA$, and has 144 atoms in the conventional unit cell, but we used in our calculations a larger $1 \times 1 \times 2$ supercell containing 288 atoms $(96 \mathrm{~T}$ and $192 \mathrm{O}$ ). The silicon framework of mordenite is composed of four- and five-membered rings, which link to form large 12-ring channels parallel to $\mathrm{c}$ interconnected via 8-ring side pockets parallel to $\mathrm{b}$ (Figure 1). Among the four non-equivalent tetrahedral sites in the mordenite unit cell, T1 is in the 12-ring main channel, T2 and $\mathrm{T} 4$ are in the intersection between the 12-ring channel and the 8ring pocket, and T3 is inside the 8-ring pocket. A Brönsted acid site was generated at $\mathrm{T} 4$ site, accessible from the 12-ring channel.

4.2. Materials. Commercial mordenite $(\mathrm{MOR}, \mathrm{Si} / \mathrm{Al}=11)$ and ZSM-5 (MFI, Si/Al=14) samples supplied by Tosoh Company, and CATAL International, respectively, were used in their protonic form. MCM-22 was synthesized following the procedure described in the literature, ${ }^{57}$ and DS-ITQ-2 was prepared as follows ${ }^{44}$ : Sodium Aluminate $\left(1.108 \mathrm{~g} ; 58.9 \% \mathrm{Al}_{2} \mathrm{O}_{3}, 38.7 \% \mathrm{Na}_{2} \mathrm{O}, 2.4 \% \mathrm{H}_{2} \mathrm{O}\right.$, Carlo Erba) and $\mathrm{NaOH}(13.666 \mathrm{~g}, 10 \%$ in water) were dissolved in doubly distilled water $(102.567 \mathrm{~g})$. Then, N-hexadecyl-N'-methylDABCO $\left(\mathrm{C}_{16} \mathrm{DC}_{1}\right)(8.951 \mathrm{~g})$ was added to the solution while stirring. When the surfactant was completely dissolved, hexamethyleneimine (4.760 g; Sigma-Aldrich) and fumed silica ( $9.614 \mathrm{~g}$; Sigma-Aldrich, particle size $=0.007 \mathrm{~mm}$ ) were added to the mixture, which was stirred vigorously for $1 \mathrm{~h}$ to obtain a gel with a molar $\mathrm{Na}_{2} \mathrm{O} / \mathrm{SiO}_{2} / \mathrm{Al}_{2} \mathrm{O}_{3} / \mathrm{HMI} / \mathrm{C}_{16} \mathrm{DC}_{1} / \mathrm{H}_{2} \mathrm{O}$ composition of $0.15: 1: 0.04: 0.3: 0.1: 40$. Finally, the gel was transferred to a $35 \mathrm{~mL}$ PTFE-lined stainless-steel autoclave, which was rotated at $60 \mathrm{rpm}$ and heated to $423 \mathrm{~K}$ for 7 days. After quenching the reaction mixture with cold water, the product was filtered, washed with distilled water until $\mathrm{pH}<9$, and dried at $373 \mathrm{~K}$ overnight. The organic material was removed by calcination in air at $813 \mathrm{~K}$ for 12 h. Physico-chemical properties of the samples are given in Table S5.

4.3. Characterization. Powder X-ray diffraction (PXRD) patterns of the calcined samples were recorded on a Philips X'Pert diffractometer equipped with a graphite monochromator, operating at $40 \mathrm{kV}$ and $45 \mathrm{~mA}$, and using nickel-filtered $\mathrm{CuK} \alpha$ radiation $(\lambda=$ $0.1542 \mathrm{~nm}$ ).

The chemical composition of the catalysts was analyzed in a 715ES ICP-optical emission spectrometer after dissolution of the solids in a $\mathrm{HNO} 3 / \mathrm{HCl} / \mathrm{HF}$ solution. Textural properties were determined from the nitrogen adsorption isotherm measured at $77 \mathrm{~K}$ on a Micrometrics ASAP 2010 volumetric adsorption analyzer. Surface area and micropore volume values were obtained by applying the BET equation and from the t-plot graph, respectively. Acidity measurements were carried out by adsorption/desorption of pyridine followed by IR spectroscopy. Self-supported wafers (10 $\mathrm{mg} \mathrm{cm}{ }^{-2}$ ) of calcined samples were activated at $673 \mathrm{~K}$ and $10^{-2} \mathrm{~Pa}$ overnight in a Pyrex vacuum cell. Then, they were allowed to come in contact with $6.5 \times 10^{2} \mathrm{~Pa}$ of pyridine vapor at room temperature and desorbed in vacuum at increasing temperatures $(423,523$ and
$623 \mathrm{~K})$. The spectra were recorded at room temperature. All the spectra were scaled according to the sample weight. Adsorption coefficients calculated by Emeis $^{58}$ were used. Analogous experiments but using 2,6-di-tert-butylpyridine (DTBPy) ${ }^{59}$ as probe molecule were also carried out to measure the external acidity.

Crystal size and morphology was determined by Transmission Electron Microscopy (TEM) using a PHILIPS CM10 microscope.

4.4. Catalytic tests. Ethylbenzene conversion experiments were conducted in a fluidized-bed batch reactor (riser simulator) because of its suitability to conduct short-contact time experiments. The fluidized CREC Riser Simulator is a bench scale equipment with internal recycle unit ${ }^{60}$ and the reactor details and the experimental procedure can be found elsewhere. ${ }^{61}$

All experiments were conducted using $0.40 \mathrm{~g}$ of catalysts. The catalysts were ground and sieved to recover the particles to the appropriate size $(60 \mu \mathrm{m})$ to be adequate for fluidization under the conditions of the CREC Riser Simulator. The mass of reactant injected was $0.081 \mathrm{~g}$, the residence times were $5,10,15$ and 20 seconds, and the tests were performed at temperatures of 573, 623 and $673 \mathrm{~K}$ and atmospheric pressure. Pure ethylbenzene was used as feed. The riser simulator was heated under continuous flow of argon (inert gas). The catalyst was thermally activated at $620^{\circ} \mathrm{C}$ for 15 minutes in a stream of air. After each run, the product gas samples were analyzed three times by automatic injection into the gas chromatograph (GC). The standard deviations at each run were found in the range of $\pm 2 \%$. The GC analyzed data were further processed to calculate the conversion, product yield and selectivity.

\section{ASSOCIATED CONTENT}

\section{Supporting Information}

DFT calculated relative stabilities and optimized geometries of reaction intermediates. Physico-chemical properties and TEM images of the catalyst samples used. Conversion and selectivities obtained at different $\mathrm{T}$ and using different catalyst samples.

\section{AUTHOR INFORMATION}

\section{Corresponding Author}

Avelino Corma, acorma@itq.upv.es

Mercedes Boronat, boronat@itq.upv.es

\section{ORCID}

Vicente Margarit: 0000-0003-1877-9422

Cristina Martinez: 0000-0002-4415-084X

Mercedes Boronat: 0000-0002-6211-5888

Avelino Corma: 0000-0002-2232-3527

Notes

The authors declare no competing financial interest.

\section{ACKNOWLEDGMENT}

This work was supported by the Spanish Government through "Severo Ochoa Program" (SEV 2012-0267; SEV-2016-0683), CTQ2015-70126-R and MAT2017-82288-C2-1-P, by the Fundación Ramón Areces through a research contract of the "Life and Materials Science" program, and by the European Union through ERC-AdG-2014-671093 (SynCatMatch). Red Española de Supercomputación (RES) and Centre de Càlcul de la Universitat de Valencia are gratefully acknowledged for computational resources and technical support. We thank the Electron Microscopy Service of the UPV for their help in sample characterization 


\section{REFERENCES}

1. Martinez, C.; Corma, A., Inorganic molecular sieves: Preparation, modification and industrial application in catalytic processes. Coord. Chem. Rev. 2011, 255, 1558-1580.

2. Davis, M. E., Ordered porous materials for emerging applications. Nature 2002, 417 (6891), 813-821.

3. Vermeiren, W.; Gilson, J.-P., Impact of Zeolites on the Petroleum and Petrochemical Industry. Top. Catal. 2009, 52, 11311161.

4. Degnan Jr, T. F., Recent progress in the development of zeolitic catalysts for the petroleum refining and petrochemical manufacturing industries. In Studies in Surface Science and Catalysis, 2007; Vol. 170, pp 54-65.

5. Perego, C.; Carati, A., Zeolites and zeolite-like materials in industrial catalysis. In Zeolites: from model materials to industrial catalysts, Cejka, J.; Perez-Pariente, J.; Roth, W. J., Eds. Transworld Research Network: Kerala, India, 2008; pp 357-389.

6. Al-Khattaf, S.; Ali, S. A.; Aitani, A. M.; Žilková, N.; Kubička, D.; Čejka, J., Recent Advances in Reactions of Alkylbenzenes Over Novel Zeolites: The Effects of Zeolite Structure and Morphology. Catalysis Reviews 2014, 56 (4), 333402.

7. Degnan Jr, T. F., The implications of the fundamentals of shape selectivity for the development of catalysts for the petroleum and petrochemical industries. J. Catal. 2003, 216 (1-2), 32-46.

8. Gallego, E. M.; Portilla, M. T.; Paris, C.; LeónEscamilla, A.; Boronat, M.; Moliner, M.; Corma, A., "Ab initio" synthesis of zeolites for preestablished catalytic reactions. Science 2017, 355 (6329), 1051-1054.

9. Van Speybroeck, V.; Hemelsoet, K.; Joos, L.; Waroquier, M.; Bell, R. G.; Catlow, C. R. A., Advances in theory and their application within the field of zeolite chemistry. Chem. Soc. Rev. 2015, 44 (20), 7044-7111.

10. Sarazen, M. L.; Iglesia, E., Effects of Charge, Size, and Shape of Transition States, Bound Intermediates, and Confining Voids in Reactions of Alkenes on Solid Acids. ChemCatChem 2018, 10 (18), 4028-4037.

11. Noh, G.; Shi, Z.; Zones, S. I.; Iglesia, E., Isomerization and B-scission reactions of alkanes on bifunctional metal-acid catalysts: Consequences of confinement and diffusional constraints on reactivity and selectivity. J. Catal. 2018, 389-410.

12. Svelle, S.; Olsbye, U.; Lillerud, K.-P.; Kolboe, S.; Bjørgen, M., Diphenylmethane-Mediated Transmethylation of Methylbenzenes over H-Zeolites. J. Am. Chem. Soc. 2006, 128 (17), 5618-5619.

13. Xiong, Y.; Rodewald, P. G.; Chang, C. D., On the mechanism of toluene disproportionation in a zeolite environment. J. Am. Chem. Soc. 1995, 117 (37), 9427-9431.

14. Demuth, T.; Raybaud, P.; Lacombe, S.; Toulhoat, H., Effects of zeolite pore sizes on the mechanism and selectivity of xylene disproportionation - A DFT study. J. Catal. 2004, 222 (2), 323-337.

15. Clark, L. A.; Sierka, M.; Sauer, J., Computational Elucidation of the Transition State Shape Selectivity Phenomenon. J. Am. Chem. Soc. 2004, 126 (3), 936-947.

16. Byun, Y.; Jo, D.; Shin, D. N.; Hong, S. B., Theoretical investigation of the isomerization and disproportionation of $\mathrm{m}$ xylene over medium-pore zeolites with different framework topologies. ACS Catal. 2014, 4, 1764-1776.

17. Min, H. K.; Hong, S. B., Mechanistic investigations of ethylbenzene disproportionation over medium-pore zeolites with different framework topologies. J. Phys. Chem. C 2011, 115 (32), 16124-16133.

18. Yi, X.; Byun, Y.; Chu, Y.; Zheng, A.; Hong, S. B.; Deng, F., Stability of the Reaction Intermediates of Ethylbenzene Disproportionation over Medium-Pore Zeolites with Different
Framework Topologies: A Theoretical Investigation. J. Phys. Chem. C 2013, 117, 23626-23637.

19. Huang, J.; Jiang, Y.; Marthala, V. R. R.; Hunger, M., Insight into the mechanisms of the ethylbenzene disproportionation: Transition state shape selectivity on zeolites. $J$. Am. Chem. Soc. 2008, 130 (38), 12642-12644.

20. Huang, J.; Jiang, Y.; Marthala, V. R. R.; Ooi, Y. S.; Hunger, M., Regioselective H/D exchange at the side-chain of ethylbenzene on dealuminated zeolite $\mathrm{H}-\mathrm{Y}$ studied by in situ MAS NMR-UV/vis spectroscopy. ChemPhysChem 2008, 9, 1107-1109. 21. Santilli, D. S., The mechanism of aromatic transalkylation in ZSM-5. J. Catal. 1986, 99 (2), 327-334.

22. Laforge, S.; Martin, D.; Paillaud, J. L.; Guisnet, M., m-Xylene transformation over H-MCM-22 zeolite: 1. Mechanisms and location of the reactions. J. Catal. 2003, 220 (1), 92-103.

23. Laforge, S.; Martin, D.; Guisnet, M., Xylene transformation over H-MCM-22 zeolites: 3 . Role of the three pore systems in o-, m- and p-xylene transformations. Appl Catal A Gen 2004, $268(1-2), 33-41$.

24. Corma, A.; Corell, C.; Llopis, F.; Martínez, A.; PérezPariente, J., Proposed pore volume topology of zeolite MCM-22 based on catalytic tests. Appl. Catal. A Gen. 1994, 115 (1), 121134.

25. Akhtar, M. N.; Tukur, N. M.; Al-Yassir, N.; Al-Khattaf, S.; Čejka, J., Transalkylation of ethyl benzene with triethylbenzene over ZSM-5 zeolite catalyst. Chem. Eng. J. 2010, 163 (1-2), 98107.

26. Guisnet, M.; Gnep, N. S.; Morin, S., Mechanisms of xylene isomerization over acidic solid catalysts. Microporous Mesoporous Mater. 2000, 35-36, 47-59.

27. Clark, L. A.; Sierka, M.; Sauer, J., Stable mechanistically-relevant aromatic-based carbenium ions in zeolite catalysts. J. Am. Chem. Soc. 2003, 125 (8), 2136-2141.

28. Rozanska, X.; van Santen, R. A.; Hutschka, F., Hafner, J. A Periodic DFT Study of Intramolecular Isomerization Reactions of Toluene and Xylenes Catalyzed by Acidic Mordenite. J. Am. Chem. Soc. 2001, 123, 7655-7667.

29. Corma, A.; Sastre, E., Evidence for a bimolecular isomerization of xylenes on some large pore zeolites. Journal of the Chemical Society, Chemical Communications 1991, (8), 594-596. 30. Philippou, A.; Anderson, M. W., Solid-state NMR investigation of ethylbenzene reactions over HMOR and Pt-HMOR catalysts. J. Catal. 1997, 167 (1), 266-272.

31. Corma, A.; Llopis, F.; Monton, J. B., Influence of the Structural Parameters of $\mathrm{Y}$ Zeolite on the Transalkylation of Alkylaromatics. J. Catal. 1993, 140 (2), 384-394.

32. Min, H. K.; Chidambaram, V.; Hong, S. B., Diethylated Diphenylethane Species: Main Reaction Intermediates of Ethylbenzene Disproportionation over Large-Pore Zeolites. $J$. Phys. Chem. C 2010, 114, 1190-1193.

33. Llopis, F. J.; Sastre, G.; Corma, A., Isomerization and disproportionation of $\mathrm{m}$-xylene in a zeolite with 9- and 10membered ring pores: Molecular dynamics and catalytic studies. $J$. Catal. 2006, 242 (1), 195-206.

34. Sastre, G.; Raj, N.; Catlow, C. R. A.; Roque-Malherbe, R.; Corma, A., Selective diffusion of C8 aromatics in a 10 and 12 MR zeolite. A molecular dynamics study. J Phys Chem B 1998, 102 (17), 3198-3209.

35. Arsenova, N.; Haag, W. O.; Karge, H. G., Kinetics study of ethylbenzene disproportionation with medium and large pore zeolites. Stud. Surf. Sci. Catal. 1997, 105B (Progress in Zeolite and Microporous Materials, Pt. B), 1293-1300.

36. Derouane, E. G.; Andre, J.-M.; Lucas, A. A., Surface curvature effects in physisorption and catalysis by microporous solids and molecular sieves. J. Catal. 1988, 110 (1), 58-73.

37. Derouane, E. G., Zeolites as solid solvents1Paper presented at the International Symposium `Organic Chemistry and 
Catalysis' on the occasion of the 65th birthday of Prof. H. van Bekkum, Delft, Netherlands, 2-3 October 1997.1. J. Mol. Catal. A Chem. 1998, 134 (1), 29-45.

38. Boronat, M.; Martinez-Sanchez, C.; Law, D.; Corma, A., Enzyme-like Specificity in Zeolites: A Unique Site Position in Mordenite for Selective Carbonylation of Methanol and Dimethyl Ether with CO. J. Am. Chem. Soc. 2008, 130, 16316-16323.

39. Boronat, M.; Corma, A., What is measured when measuring acidity in zeolites with probe molecules? ACS Catal. 2019, 9 (2), 1539-1548.

40. Gounder, R.; Iglesia, E., Effects of partial confinement on the specificity of monomolecular alkane reactions for acid sites in side pockets of mordenite. Angew. Chem. Int. Ed. 2010, 49 (4), 808-811.

41. Gounder, R.; Iglesia, E., The catalytic diversity of zeolites: Confinement and solvation effects within voids of molecular dimensions. Chem. Commun. 2013, 49 (34), 3491-3509. 42. $\quad$ Mansoor, E.; Van der Mynsbrugge, J.; Head-Gordon, M.; Bell, A. T. Impact of long-range electrostatic and dispersive interactions on theoretical predictions of adsorption and catalysis in zeolites. Catal. Today 2018, 312, 51-65.

43. Li, C.; Paris, C.; Martínez-Triguero, J.; Boronat, M.; Moliner, M.; Corma, A., Synthesis of reaction-adapted zeolites as methanol-to-olefins catalysts with mimics of reaction intermediates as organic structure-directing agents. Nature Catalysis 2018, 1 (7), 547-554.

44. Margarit, V. J.; Martínez-Armero, M. E.; Navarro, M. T.; Martínez, C.; Corma, A., Direct Dual-Template Synthesis of MWW Zeolite Monolayers. Angew. Chem. Int. Ed. 2015, 54 (46), 13724-13728.

45. Sievers, C.; Onda, A.; Guzman, A.; Otillinger, K. S.; Olindo, R.; Lercher, J. A. Low-Temperature Activation of Branched Octane Isomers over Lanthanum-Exchanged Zeolite X Catalysts, J. Phys. Chem. C 2007, 111, 210-218.

46. Corma, A.; Planelles, J.; Sanchez-Marín, J.; Tomás, F., The Role of Different Types of Acid Site in the Cracking of Alkanes on Zeolite Catalysts. J. Catal. 1985, 93, 30-37.

47. Karge, H. G.; Ernst, S.; Weihe, M.; Weiss, U.; Weitkamp, J., Ethylbenzene disproportionation over large pore zeolites. Stud. Surf. Sci. Catal. 1994, 84 (Zeolites and Related Microporous Materials, PT. C), 1805-12.

48. Serra, J. M.; Guillon, E.; Corma, A., A rational design of alkyl-aromatics dealkylation-transalkylation catalysts using C8 and C9 alkyl-aromatics as reactants. J. Catal. 2004, 227 (2), 459-469.

49. Arsenova-Härtel, N.; Bludau, H.; Haag, W. O.; Karge, H. G., Influence of the zeolite pore structure on the kinetics of the disproportionation of ethylbenzene. Microporous Mesoporous Mater. 2000, 35-36, 113-119.

50. Park, S.-H.; Rhee, H.-K., Shape selective properties of MCM-22 catalysts for the disproportionation of ethylbenzene. Appl Catal A Gen 2001, 219 (1-2), 99-105.

51. Perdew, J. P.; Chevary, J. A.; Vosko, S. H.; Jackson, K. A.; Pederson, M. R.; Singh, D. J.; Fiolhais, C., Atoms, molecules, solids, and surfaces: Applications of the generalized gradient approximation for exchange and correlation. Physical Review $B$ 1992, 46 (11), 6671-6687.

52. Perdew, J. P.; Wang, Y., Accurate and simple analytic representation of the electron-gas correlation energy. Physical Review B 1992, 45 (23), 13244-13249.

53. Kresse, G.; Furthmüller, J., Efficient iterative schemes for ab initio total-energy calculations using a plane-wave basis set. Physical Review B 1996, 54 (16), 11169-11186.

54. Blöchl, P. E., Projector augmented-wave method. Physical Review B 1994, 50 (24), 17953-17979.

55. Grimme, S., Accurate description of van der Waals complexes by density functional theory including empirical corrections. Journal of Computational Chemistry 2004, 25 (12), 1463-1473.

56. Grimme, S., Semiempirical GGA-type density functional constructed with a long-range dispersion correction. Journal of Computational Chemistry 2006, 27 (15), 1787-1799.

57. Corma, A.; Fornes, V.; Pergher, S. B.; Maesen, T.; Buglass, J. G., Delaminated zeolite precursors as selective acidic catalysts. Nature (London) 1998, 396 (6709), 353-356.

58. Emeis, C. A., Determination of Integrated Molar Extinction Coefficients for Infrared Absorption Bands of Pyridine Adsorbed on Solid Acid Catalysts. J. Catal. 1993, 141 (2), 347354.

59. Corma, A.; Fornés, V.; Forni, L.; Márquez, F.; Martínez-Triguero, J.; Moscotti, D., 2,6-Di-Tert-Butyl-Pyridine as a Probe Molecule to Measure External Acidity of Zeolites. J. Catal. 1998, 179 (2), 451-458.

60. de Lasa, H. I. Riser simulator for catalytic cracking studies. U.S. Patent 5,102,628., 1991

61. Al-Khattaf, S.; De Lasa, H., The role of diffusion in alkyl-benzenes catalytic cracking. Appl Catal A Gen 2002, 226 (12), 139-153. 


\section{Control of the Reaction Mechanism of Alkylaromatics Transalkylation by Means of Molecular Confinement Effects Associated to Zeolite Channel Architecture}

Vicente J. Margarit, ${ }^{1}$ Mogahid Osman, ${ }^{2}$ Sulaiman Al-Khattaf, ${ }^{2}$ Cristina Martínez, ${ }^{1}$ Mercedes Boronat, ${ }^{1 *}$ and Avelino Corma ${ }^{{ }^{*}}$

${ }^{1}$ Instituto de Tecnología Química, Universitat Politècnica de València - Consejo Superior de Investigaciones Cientificas, Av. de los Naranjos, s/n, 46022 Valencia, Spain

${ }^{2}$ Center of Research Excellence in Petroleum Refining \& Petrochemicals, King Fahd University of Petroleum \& Minerals, 31261 Dhahran, Saudi Arabia

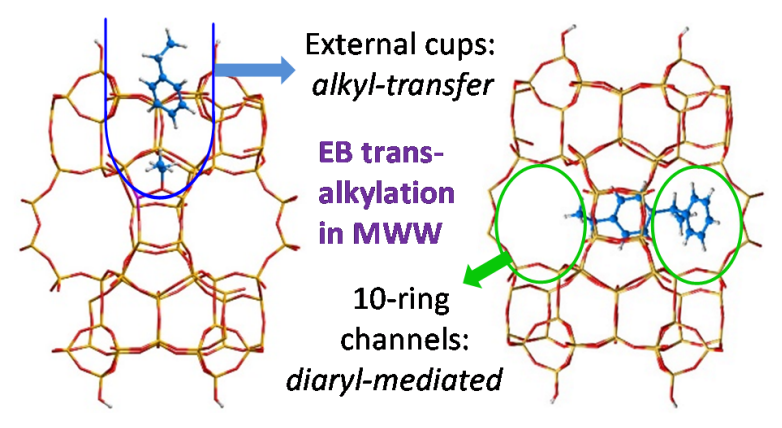

